\title{
A quantitative infection assay for human type I, II, and III interferon antiviral activities
}

Emily Voigt ${ }^{1,2+}$, Bahar İnankur ${ }^{1,2+}$, Ashley Baltes ${ }^{1,2}$ and John Yin ${ }^{1,2^{*}}$

\begin{abstract}
Background: Upon virus infection, cells secrete a diverse group of antiviral molecules that signal proximal cells to enter into an antiviral state, slowing or preventing viral spread. These paracrine signaling molecules can work synergistically, so measurement of any one antiviral molecule does not reflect the total antiviral activity of the system.

Results: We have developed an antiviral assay based on replication inhibition of an engineered fluorescent vesicular stomatitis virus reporter strain on A549 human lung epithelial cells. Our assay provides a quantitative functional readout of human type I, II, and III interferon activities, and it provides better sensitivity, intra-, and interassay reproducibility than the traditional crystal violet based assay. Further, it eliminates cell fixation, rinsing, and staining steps, and is inexpensive to implement.

Conclusions: A dsRed2-strain of vesicular stomatitis virus that is sensitive to type I, II, and III interferons was used to develop a convenient and sensitive assay for interferon antiviral activity. We demonstrate use of the assay to quantify the kinetics of paracrine antiviral signaling from human prostate cancer (PC3) cells in response to viral infection. The assay is applicable to high-throughput screening for anti-viral compounds as well as basic studies of cellular antiviral signaling.
\end{abstract}

Keywords: Antiviral activity assay, Reporter virus, Interferon, Paracrine signaling, Bioassay, Cytokine quantification

\section{Background}

Mammalian cells respond to virus infection by synthesizing and secreting a host of antiviral molecules that are not only involved in recruitment of immune effector cells and activation of adaptive immunity, but also control localized spread of virus infection via mechanisms of "cell-intrinsic" innate immunity. These secreted antiviral molecules, first described collectively in 1957 as "interferon", establish an anti-viral state within the infected cell, and signal other cells to react in an antiviral manner [1,2].

Antivirals secreted by non-immune cells comprise a diverse mixture of molecules which exert a combined paracrine effect on proximal cells. These include, for example, the classic type I interferons (IFN $\alpha / \beta$, etc.) $[3,4]$, type II interferon (IFN $\gamma$ ), and type III interferons (IFN $\lambda s$ )

\footnotetext{
*Correspondence: yin@engr.wisc.edu

${ }^{\dagger}$ Equal contributors

'Department of Chemical and Biological Engineering, University of Wisconsin, Madison, USA

${ }^{2}$ Systems Biology Theme, Wisconsin Institute for Discovery, 330 N Orchard St. Madison, WI 53715, USA
}

[5-9]. While type I interferons are known to play important roles in host antiviral responses, for many viruses such as human rhinovirus and influenza infections of bronchial epithelial cells, other interferons such as the more recently identified IFN $\lambda \mathrm{s}$, may dominate [10,11]. Thus, measuring type I IFNs alone does not necessarily accurately assess cellular antiviral responses, and an assay that measures antiviral responses due to multiple types of interferons is required.

The biological effects of interferons are often measured using reporter gene assays (RGAs), which use transgenic cell lines expressing a reporter gene driven by an IFNresponsive promoter [12-17]. These assays accurately measure the presence or upregulation of single molecules, such as Mx or various interferon-stimulated genes, and provide valuable information on specific components of an antiviral response. However, other assay methods are necessary for the quantification of the integrated antiviral effects of multiple-type interferon signaling, which is essential for studying inhibition of virus spread $[18,19]$. Moreover, functional measures of secreted antiviral

\section{Biomed Central}


signaling will be useful for advancing experimental and computational models of virus-cell interactions and viral infection spread in monolayers and tissues [20-24]. Such an assay potentially has additional applications in the area of high-throughput screening for antiviral compounds.

The most traditional form of a functional antiviral assay is the assay based on cytopathic effect (CPE), commonly used to determine the potency of purified interferon stocks. In the CPE assay, antiviral activity is measured based on its ability to inhibit virus-induced cytopathology as measured by a crystal violet live-cell stain [25]. While widely used, these types of assays are labor-intensive and contain many handling steps that can disturb cell layers and increase variability. Additionally, successful infection that does not cause major cytopathology is not detected by these assays. These shortcomings can be addressed through the development of reporter virus strains as robust readouts of virus replication. Examples include a luciferase-expressing reporter strain of the BSL3 Rift Valley Fever virus and a nonproliferative vesicular stomatitis virus (VSV) replicon also expressing luciferase [2,26]. Here we create a replicationcompetent fluorescent reporter VSV strain. We use this virus in a simple, sensitive, and reproducible assay for detection of secreted antiviral signaling activity. The assay does not require the addition of expensive substrates eliminates cell fixing, rinsing, and staining steps, and significantly improves sensitivity, and reproducibility over the traditional crystal violet CPE assay. Additionally, the broad tropism of VSV allows for potential future assay adaptation to a large range of host cell types [2,26].

\section{Results}

\section{Synthesis of reporter virus constructs}

We sought to create an assay to quantify overall activity of secreted antiviral molecules with optimal sensitivity and reproducibility. We therefore compared four detection methods to determine antiviral activity: the traditional crystal violet live-cell stain, Sytox ${ }^{\oplus}$ orange, a fluorescent dead cell stain, and both a DsRed2-expressing and a ZsGreen-expressing VSV reporter strain. Using fluorescent reporters of VSV replication may increase assay sensitivity, as inhibition of virus replication is a more direct measure of antiviral activity than cytopathology alone. We created strains of DsRed2- or ZsGreen-encoding VSV with genomic organization as indicated in Figure 1 for use in our antiviral assays. We tested the ability of these recombinant virus strains to infect A549 lung epithelial cells, and found their replication rates comparable to that of their nonfluorescent equivalent (Additional file 1: Figure S1) and a multiplicity of infection (MOI) of 5 pfu/cell sufficient to homogenously infect A549 monolayers (data not shown).

\section{Comparison of assay readout methods}

We compared the traditional virus-induced cytopathology measurement (crystal violet after 28-hour infection) with a more recently developed fluorescent dead cell stain $\left(\right.$ Sytox $\left.^{\odot}\right)$ and our two fluorescent VSV reporter strains. To do so, we incubated A549 cells under 2-fold dilutions of an IFN $\beta$ standard solution in media for 24 hours. The cells were then infected with either wild-type or one of the fluorescent reporter VSV strains as indicated in Figure 2, at an MOI of $5 \mathrm{pfu} / \mathrm{cell}$, and the infection was allowed to progress for 28 hours. WtVSV-infected plates were rinsed and stained as indicated. Assay results were quantified by fluorescent scanning at the appropriate wavelengths and subsequent normalization to positive (no IFN) and negative (no virus) controls, as shown in Figure 2.

We found that the fluorescent signal from DsRed 2 and ZsGreen reporter viruses created reproducible gradients indicating decreasing viral replication due to increasing IFN concentrations. These gradients were comparable to those found by staining cells with crystal violet after wtVSV replication and cell death. Sytox ${ }^{\oplus}$ fluorescent dead cell stain also produced quantifiable gradients, but with a significantly poorer antiviral detection limit $\left(\mathrm{IC}_{50}=7.87\right.$ $\mathrm{U} / \mathrm{ml}$ vs. $<4 \mathrm{U} / \mathrm{ml}$ ) than both crystal violet and fluorescent virus assays.

\section{Sensitivity and reproducibility comparison of fluorescent reporter viruses}

As fluorescent signals are generally more sensitive than readouts of absorbance, and dead-cell stains require fixing and staining steps that can disturb cell layers and increase variability, we tested the reproducibility and sensitivity

\begin{tabular}{|c|c|c|c|c|c|c|c|}
\hline wtVSV & $3-\mathrm{N}$ & $P$ & $\mathrm{M}$ & G & & $\mathrm{L}$ & -5 \\
\hline VSV-ZsGreen1-DR & $3-N$ & $P$ & $M$ & $\mathrm{G}$ & ZsGreen & & $\mathrm{L}$ \\
\hline VSV-DsRed2 & $3-N$ & $P$ & $\mathrm{M}$ & $\mathrm{G}$ & DsRed2 & & $\mathrm{L}$ \\
\hline
\end{tabular}

Figure 1 Genotype maps of wild-type and fluorescent reporter VSV strains used in this study. Recombinant VSV strains were created by reverse-genetics, incorporating fluorescent reporter variants of GFP(ZsGreen) and RFP(DsRed2) along with the five native VSV proteins: nucleocapsid protein $(N)$, phosphoprotein $(P)$, matrix protein $(M)$, glycoprotein $(G)$, and large protein $(L)$. 


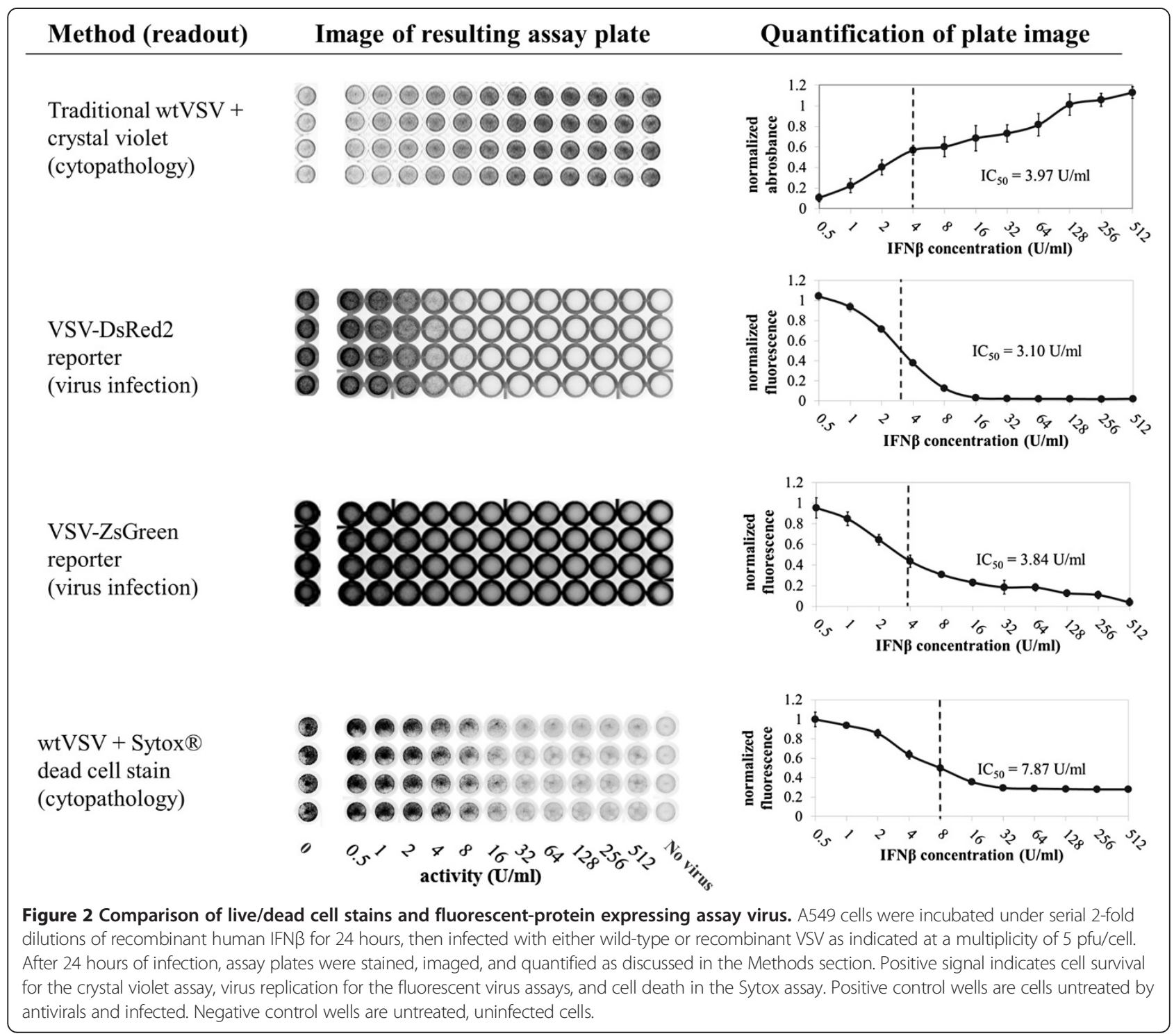

of assays using ZsGreen and DsRed2 reporter virus and compared it to that of the traditional crystal violet cytopathology-based assay. Fluorescence was read both on a standard fluorescent plate reader and also scanned with a high-resolution GE Typhoon FLA 9000 Biomolecular Imager, to determine which reading method is more sensitive and reproducible. Sensitivity was defined as the limit of detection (LOD), the lowest antiviral starting dose that, upon two-fold serial dilution, would produce a doseresponse curve crossing the $50 \%$ viral inhibition point and allow for accurate $\mathrm{IC}_{50}$ determination, as shown in Table 1. Calculation of $\mathrm{IC}_{50}$ values for both quantification types was done using linear interpolation within the linear dosedependent range of the indicated interferon treatment as described in Methods. A sigmoidal-fit $\mathrm{IC}_{50}$ calculation method was also tested, but showed no advantage over linear interpolation.
Both fluorescent reporter viruses significantly decreased the limit of detection and improved intra- and inter-assay reproducibility over the traditional crystal violet staining method. Sensitivity differences between DsRed2 and ZsGreen were insignificant $(\mathrm{p}>0.1)$. The DsRed reporter virus showed better inter-assay reproducibility than the ZsGreen virus when quantified by fluorescent scanning. This may be due to fluorescent background in the green absorption/emission spectrum produced by the plastic microtiter plate (Figure 3). There was no significant difference between the reporter viruses for the plate reader quantification $(p$-value $=0.44)$.

\section{Optimization of fluorescent signal}

We determined the optimal time for signal development by measuring a time course over 28 hours of signal development as shown in Figure 3. As time progresses, the 
Table 1 Assay statistics and reproducibility

\begin{tabular}{|c|c|c|c|c|c|c|c|}
\hline \multicolumn{8}{|c|}{ A. Fluorescent plate scanner and whole-well signal integration } \\
\hline & & \multirow{2}{*}{ Sensitivity (LOD) units/ml } & \multicolumn{4}{|c|}{ Variability intra-assay COV (\%) } & \multirow{2}{*}{ Variability inter-assay COV (\%, } \\
\hline & & & Assay1 & Assay 2 & Assay 3 & Assay 4 & \\
\hline \multirow{2}{*}{ IFNa } & VSV-DsRed2 & $1.51+/-0.12$ & 0.9 & 2.9 & 0.7 & 1.7 & 2.4 \\
\hline & VSV-ZsGreen & $2.07+/-0.94$ & 1.8 & 8.6 & 5.5 & 3.3 & 16.0 \\
\hline \multirow{2}{*}{ IFNB } & $\underline{\text { VSV-DsRed2 }}$ & $1.71+/-0.27$ & 1.4 & 1.1 & 0.6 & 1.0 & 5.1 \\
\hline & VSV-ZsGreen & $2.57+/-0.52$ & 1.9 & 4.1 & 2.2 & 3.2 & 7.9 \\
\hline \multicolumn{8}{|c|}{ B. Fluorescence/absorbance plate reader } \\
\hline & & \multirow{2}{*}{ Sensitivity (LOD) units/ml } & \multicolumn{4}{|c|}{ Variability intra-assay COV (\%) } & \multirow{2}{*}{ Variability inter-assay COV (\% } \\
\hline & & & Assay 1 & Assay 2 & Assay 3 & Assay 4 & \\
\hline & VSV-DsRed2 & $1.29+/-0.34$ & 4.0 & 1.7 & 1.9 & 5.7 & 5.7 \\
\hline \multirow[t]{3}{*}{$\mathrm{IFNa}$} & VSV-ZsGreen & $0.96+/-0.18$ & 1.2 & 1.1 & 1.7 & 2.5 & 3.6 \\
\hline & Crystal violet & $4.09+/-0.43$ & 17.5 & 14.0 & 7.3 & 8.6 & 21.9 \\
\hline & VSV-DsRed2 & $2.71+/-0.29$ & 3.0 & 1.8 & 1.7 & 3.6 & 6.4 \\
\hline \multirow[t]{2}{*}{ IFNB } & VSV-ZsGreen & $1.87+/-0.11$ & 2.3 & 3.1 & 0.7 & 1.8 & 4.4 \\
\hline & Crystal violet & $8.44+/-2.28$ & 20.1 & 6.6 & 4.3 & 7.3 & 18.5 \\
\hline
\end{tabular}

Viral replication reporters and two methods of signal measurement were tested for the functional antiviral assays and calculated $\mathrm{IC}_{50}$ values statistically compared with the traditional crystal violet antiviral assay. Coefficients of variance were calculated with a minimum of four replicates. $+/-$ values are $95 \%$ confidence intervals over all samples.
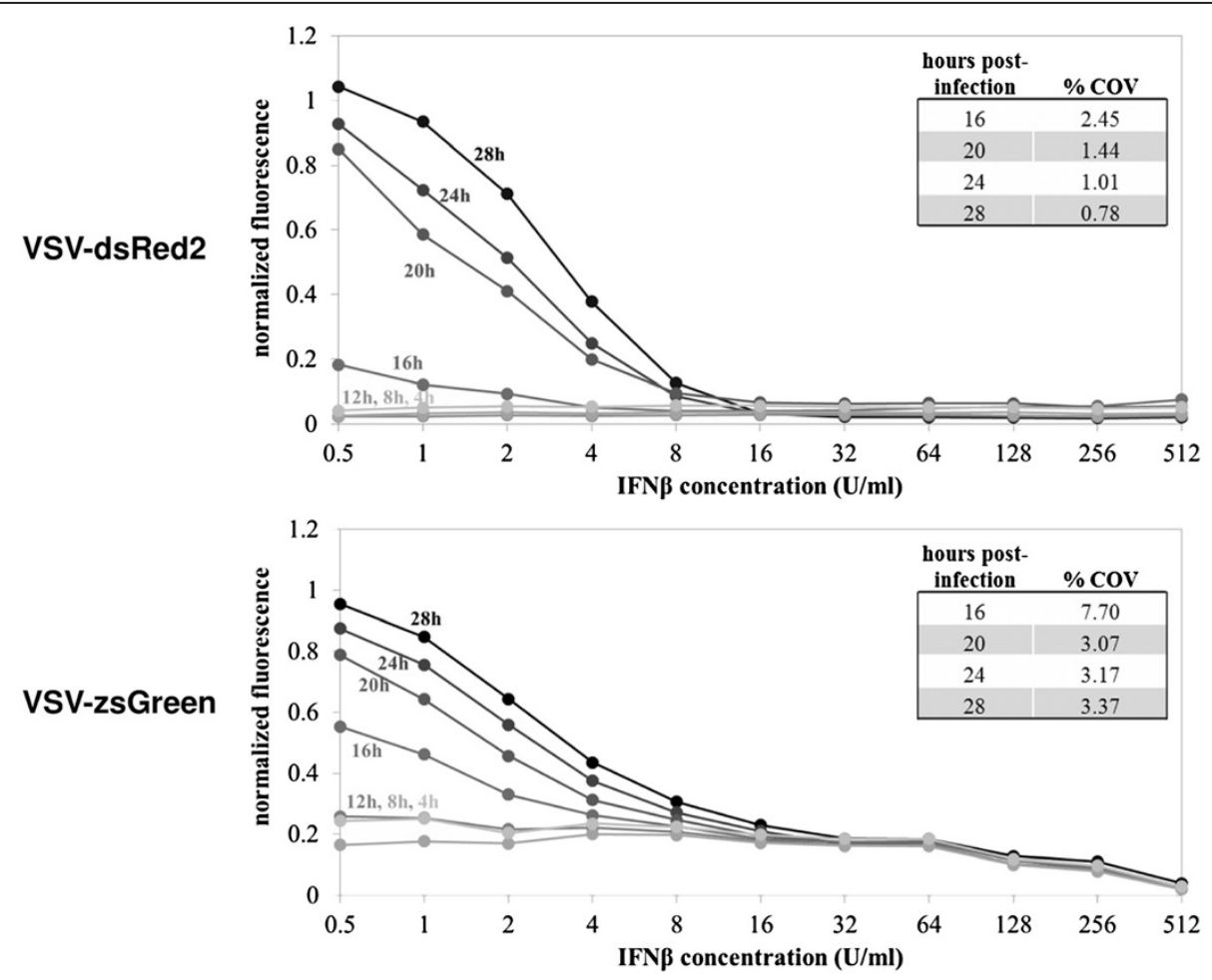

Figure 3 Assay time-course development. Recombinant VSV antiviral activity assays were imaged on a fluorescent biomolecular imager every four hours post-infection to monitor fluorescent signal development indicating viral replication. Mean fluorescence values were extracted from plate images, normalized to positive and negative controls and plotted. Darker markers indicate longer development times. $I_{50}$ values were calculated as described, and the coefficient of variance was calculated between four replicates at each time point. 
dose-dependent signal gradient develops, where higher fluorescent intensity was observed at low interferon concentrations where reporter virus replicates more productively. We found that a gradient sufficient for $\mathrm{IC}_{50}$ calculation first develops for the DsRed2 virus 16 hours post-infection. The coefficient of variance decreases until 28 hours post-infection, but met our goal of $1 \%$ coefficient of variance as early as 24 hours post-infection. This gradient shows a linear range between 0.5 and 16 units $/ \mathrm{ml}$. The minimum measurable $\mathrm{IC}_{50}$ for each set of conditions was between 1-3 units/ml for IFN $\beta$, comparable to other published assays $[2,6,12,14-17]$. The coefficient of variation for the $\mathrm{ZsGreen} \mathrm{IC}_{50}$ improves until 20 hours, then levels off but remains considerably higher than for the VSV-DsRed2 assay. From these results, the VSV-DsRed2 assay developed for 24-28 hours appears optimal, providing excellent sensitivity, reproducibility and lowest background. We chose a development time of 24 hours as our standard for convenience. Our final assay procedure and comparison to the traditional crystal violet assay is shown in Table 2 .

\section{Validation of assay against human type I, II, and III interferons}

We tested the ability of the assay to detect antiviral activity of several human type I, II, and III interferons, using the final assay method as described in Table 2. Recombinant human interferons $\alpha 1$ and $\beta$ were used to represent type I IFNs, IFN $\gamma$ was tested as the sole type II IFN, and interferons $\lambda 1$ (IL-29), $\lambda 2$ (IL-28A) and $\lambda 3$ (IL-28B) represented type III IFNs. Antiviral activity was successfully detected and measured from all IFN samples using our assay, as shown in Figure 4. $\mathrm{IC}_{50}$ concentrations were lowest for IFN $\beta$, and highest for IFN $\gamma$, as expected. As the antiviral effects of IFN $\gamma$ are largely due to cell-mediated and adaptive immune responses absent in our assay, we measured only the direct antiviral effects of IFN $\gamma$ which are far less potent than the type I and III interferons.

\section{Demonstration of the assay to measure antivirals produced in response to VSV infection}

Finally, we tested the suitability of our assay for measuring the kinetics of secretion of antiviral factors by another human cell type infected with virus. We infected parallel wells of prostate cancer (PC3) cells at MOI 50 with M51R-mutant VSV, a strain that is attenuated in its ability to block the cellular antiviral response to infection [27]. Supernatants were sampled from parallel wells over the course of infection. The titer of the supernatant samples was measured by plaque assay. Separate aliquots of supernatant were UV-irradiated to deactivate live virus, serially diluted, and assayed (Figure 5).

Extracellular antiviral activity was first detected between 6 and 8 hours post-infection (hpi), rapidly rising from 8 to $12 \mathrm{hpi}$, concurrent with the release of virus progeny. The antiviral activity continued to increase at a slower rate from 12 to 24 hpi before reaching a plateau. The range of activity, which spanned four orders of magnitude, represents the collective effects of all secreted and extracellular factors that trigger antiviral responses in A549 cells, independent of their specific pathways. This highlights the ability of this method to capture an integrated picture of the antiviral response.

\section{Discussion}

We have developed a functional antiviral assay, based on the inhibition of fluorescence produced during infection by an engineered RFP reporter strain of vesicular stomatitis virus, which can be used to report the combined antiviral activity of human interferons $\alpha, \beta, \gamma, \lambda 1, \lambda 2$, and $\lambda 3$. The assay shows an improvement in reproducibility over most published assays, including more recently published assays using luciferase reporter viruses or cells. Sensitivity of the assay, as defined as the low limit of detection, is also comparable to luciferase-based antiviral assays. However, the linear range of luciferase assays has a higher saturation concentration than the assay presented here, so further dilution of antiviral sample may sometimes be necessary when using this method (see Additional file 2: Table S1 for assay comparisons). The fluorescent reporter virus used in this assay is also easily propagated on standard laboratory cell lines, as opposed to non-replicative particles [28], leading to cheaper, more renewable and readily available assay reagents. Additionally, the assay avoids the use of luciferase reagents $[2,12,14,28]$ which increase assay expense, and eliminates many handling steps which can introduce variability and error.

Table 2 Comparison of infection reporter assay and the traditional crystal violet antiviral assay

\begin{tabular}{|c|c|c|}
\hline & Crystal violet assay & VSV-DsRed2 assay \\
\hline Antiviral incubation & 24 hours, 67ul sample & 24 hrs, 67ul sample \\
\hline Infection & wt virus, 24 hour incubation & RFP reporter virus, 24 hour incubation \\
\hline Fixation & $4 \%$ PFA in $5 \%$ sucrose, $20 \mathrm{~min}$ & \\
\hline Rinse & $2 \times \mathrm{PBS}$ & \\
\hline Stain & Addition of crystal violet, overnight incubation & \\
\hline Scan & Microplate reader at $570 \mathrm{~nm}$ & Fluorescent microplate reader $485 / 620$ or fluorescent scanner $555 / 580 \mathrm{~nm}$. \\
\hline
\end{tabular}




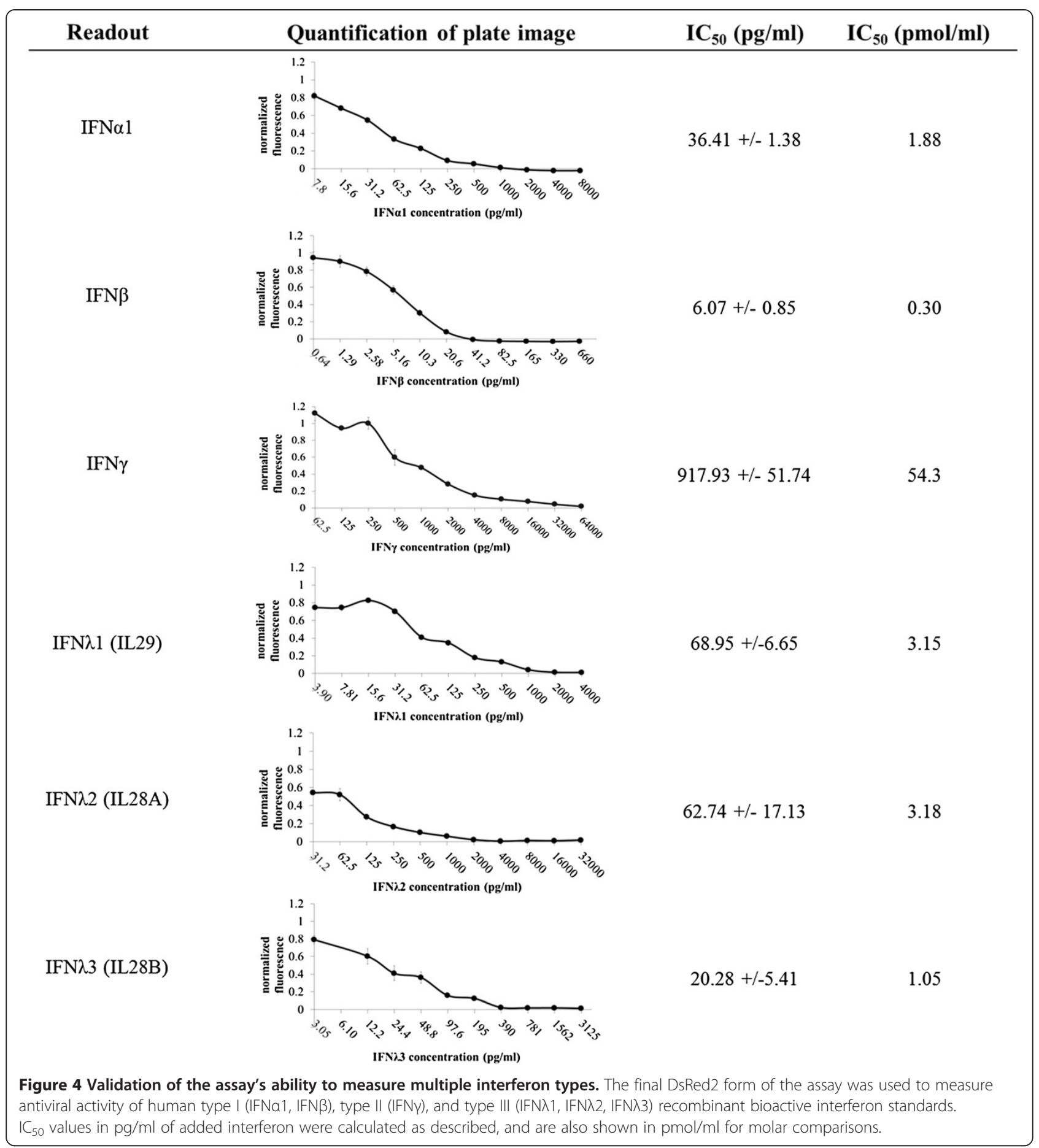

VSV is highly sensitive to interferon signaling, making it a good choice to assay for antiviral activities. However, if the ability of antiviral signaling molecules to inhibit specific viruses is of interest, or signaling in other tissue types is to be more closely investigated, this assay could likely be adapted for a multitude of virus/cell combinations. Fluorescent-expressing viruses are common throughout virological research, allowing this method to be adapted with a minimum of reagent development. Additionally, the assay could potentially be usable for measuring antiviral paracrine signals from samples obtained in vivo, such as irradiated serum and nasal lavage. Due to its ease and low expense, it could also be applied to the high-throughput screening of small molecules for antiviral properties. 


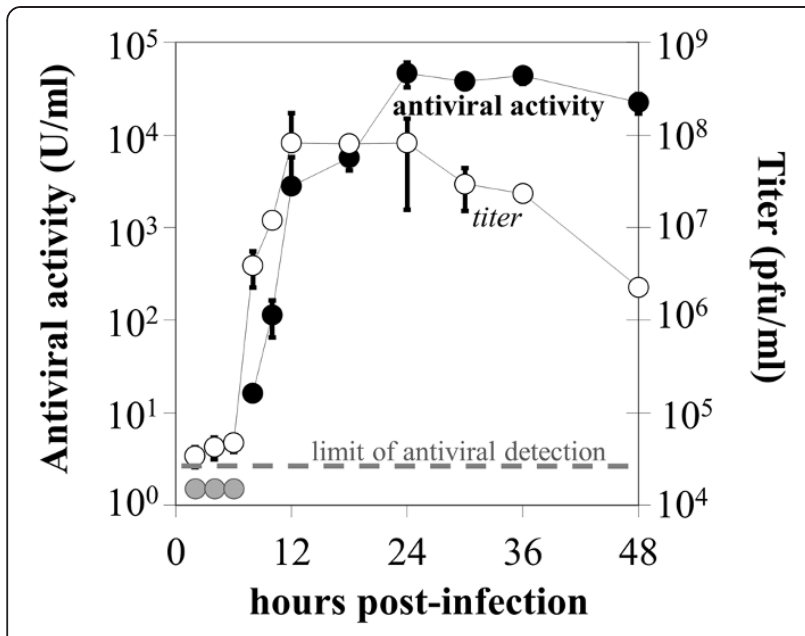

Figure 5 Kinetics of functional antiviral signaling and virus progeny release of PC 3 cells in response to virus infection. Data points are averages of biological duplicates assayed in duplicate (titer) or quadruplicate (activity). Three antiviral activity data points $(2,4$, and 6 hours post-infection) resulted in antiviral signal beneath the assay detection limit (grey). Closed symbols: antiviral activity. Open symbols: viral titer. Error bars are $+/-$ standard deviation.

In contrast to most other published assays, our assay is non-specific to a particular signaling pathway or network, providing a measure that is complementary to pathway-specific assays using bioengineered reporter cells $[12,14,16]$. The assay can thus be used to detect the collective effects of antiviral secreted factors from various antiviral pathways. We note, however, that since antiviral responses can be cell-type dependent, the use of A549 cells makes this assay most suitable for studies of antiviral secretions from respiratory cells. As such, our assay is best suited for studies of early cellular responses to upper respiratory tract infections, such as influenza A, respiratory syncytial virus, and some rhinoviruses. Additionally, our assay is not limited to quantifying the antiviral activity of interferons. Other secreted potentially antiviral molecules include interferon-stimulated gene 15 (ISG15) [29-31], inflammatory factors such as TNFa and IL-1 $\beta$ [32-34], and other species with antiviral function such as various interleukins [35-37], interferon gammainduced protein 10 (IP-10), and antiviral microRNAs [38-40]. While we have not specifically tested the ability of our assay to detect these molecules, they may well contribute to the antiviral signal reported by our assay when testing cellular or tissue responses to infection.

Extrapolation and application of any quantitative, kinetic results obtained in cultured transformed cells to an in vivo system should only be done with discretion. However, characterizing the paracrine antiviral responses of cultured cells and the integrated effects of the multiple types of released interferons is important to better understand the complex interaction of antiviral signaling and virus spread throughout more intricate tissue systems.

\section{Conclusions}

The assay presented here provides a functional measurement of antiviral activity of recombinantly expressed or cellullarly secreted human type I, III, and III interferons. It quantifies the potentially synergistic combination of antiviral activities due to multiple types of interferons in a biological sample, and is therefore complementary to pathway-specific measures of cell responses.

\section{Methods}

\section{Cell culture}

Human lung epithelial carcinoma (A549, ATCC CCL-185) and human prostate cancer (PC3, ATCC CRL-1435) cells were obtained from American Type Culture Collection and grown in RPMI 1640 medium $\left(\mathrm{Gibco}^{\circ}\right)$ supplemented with 10\% fetal bovine serum (FBS) (Atlanta Biologicals, Lawrenceville, GA). Baby hamster kidney (BHK-21) cells for plaque assays, originally obtained from Isabel Novella (University of Toledo), were grown in minimal essential medium (MEM, Corning) with 10\% FBS and $2 \mathrm{mM}$ Glutamax I $\left(\mathrm{Gibco}^{\circ}\right)$. All cell lines were cultured in a humidified incubator at $37^{\circ} \mathrm{C}$ in $5 \% \mathrm{CO}_{2}$. Cells lines were tested for mycoplasma contamination on a monthly basis.

\section{Cytokines and reagents}

Universal type I interferon (human interferon alpha A/D, IFN $\alpha$ ) and recombinant human IFN beta 1a (IFN $\beta$ ) were purchased from PBL InterferonSource (Piscataway, NJ). Interferon antiviral activity levels in units/ml were confirmed by comparison with NIH standard Human Interferon Beta (NR-3080) as obtained from BEI Resources using the traditional interferon activity assay (VSV/A549) as described below. Sytox ${ }^{\circ}$ Orange nucleic acid dead cell stain was obtained as a $5 \mathrm{mM}$ solution in DMSO from Invitrogen and used at a final concentration of $0.25 \mu \mathrm{M}$. Crystal violet was obtained from PML Microbiologicals.

Recombinant human interferons alpha 1a, gamma, lambda 1, lambda 2, and lambda 3 were obtained from Cell Signaling Technology (Danvers, MA).

All experimental research in this work was done under the oversight of the University of Wisconsin Institutional Biosafety Committee and Office of Biological Safety. No human or animal subjects were used.

\section{Virus strains}

Fluorescent VSV reporter virus strains incorporating either ZsGreen or DsRed2 into the fifth genomic position of VSV-Indiana were created using published reverse genetics techniques $[41,42]$. Adapted plasmids pBS-N, pBS-P, pBS-L, and pVSVFL (+) [42], for the 
expression of VSV N, P, and L genes and antigenomic VSV RNA under a T7 promoter were generously provided by Dr. Valery Grdzelishvili [43]. ZsGreen1-DR and DsRed2 genes (Clontech, Mountain View, CA) were PCR-amplified with the following primers and inserted into plasmid $\operatorname{pVSVFL}(+)$ in the fifth gene position:

\section{ZsGreen For 5'-aactcaaatcctgtatgaaaaaaactaacagatat ccgtacggccaccatggcccagtcc-3', DsRed2 For 5'-aactcaaatcctgtatgaaaaaaactaacagatat ccgtacggccaccatggcctcctcc-3', ZsGreen Rev 5' -gaagaatctggctaggagtcgcggccgcctacaca-3', and \\ DsRed2 Rev 5' -gaagaatctggctagcgctacaggaacaggtggtgg- ${ }^{\prime}$.}

These primers incorporated an overlap with plasmid pVSVFL(+) digested with NheI (overlap underlined) for In-Fusion Cloning (Clontech) as well as an additional VSV transcription unit (italicized) [44]. Successful insertion of the fluorescent protein genes into plasmid pVSVFL $(+)$ was confirmed via Sanger sequencing.

In addition to the fluorescent VSV reporter strains, a recombinant VSV strain with a well-studied mutation to the $M$ protein was created. This methionine to arginine substitution at the $51^{\text {st }}$ amino acid abolishes the ability of VSV $M$ protein to inhibit host cell gene expression $[45,46]$. The M51R mutation was introduced to the $M$ protein region of the genome via multistep PCR site-directed mutagenesis with the following primers (mutation in bold).

\section{XbaI For $5^{\prime}$-ttgttctcatctagaggagagttcatctctgtcggaggtgac- $3^{\prime}$ M51R Rev 5'-attcggatcataggtgtccctctcgtcaactccaaa- $3^{\prime}$ \\ M51R For $5^{\prime}$-tttggagttgacgagagggacacctatgatccgaat- $3^{\prime}$ \\ NheI Rev $5^{\prime}$-gaagaatctggctagcaggatttgagttactttccaagtcgg- $3^{\prime}$}

PCR reaction A used primers Xbal For and M51R Rev, and PCR reaction $B$ used primers M51R For and NheI Rev. These PCR reactions both created fragments with the desired mutation, and because primers M51R For and M51R Rev are reverse compliments of each other, the products from PCR reactions A and B overlap for 36 bases. Products A and B were mixed and used as templates with primers XbaI For and NheI Rev in a third PCR reaction to produce a DNA fragment that spanned between two unique restriction enzyme sites and contained the desired M51R mutation. This fragment was then cloned into pVSVFL(+) digested with XbaI and NheI.

The presence of the desired mutation was confirmed in the plasmid and recovered infectious VSV via Sanger sequencing.

Infectious VSV was recovered from plasmid with T7 expressing vaccinia virus (VVT7), also from Valery Grdzelishvili, on BHK cells at $36^{\circ} \mathrm{C}$ as previously described [41,42,47]. Recovered VSV was separated from VVT7 via filtration with a $0.22 \mu \mathrm{m}$ Millex GV filter unit (Millipore, Billerica, MA), amplified for 2 days on BHK cells, and plaque purified. A master and subsequent working stock of recovered recombinant VSV were created from a single plaque. Growth curves confirmed the recombinant VSV strains to have similar growth rates as recombinant wtVSV (Additional file 1: Figure S1).

\section{Antiviral activity assay}

$67 \mu \mathrm{l} /$ well of A549 cells were seeded into 96-well microtiter plates at a density of $2.5 \times 10^{5}$ cells $/ \mathrm{ml}$ and cultured for $24 \mathrm{~h}$ before antiviral treatment. Interferon was diluted serially 1:2 in RPMI media supplemented with $2 \%$ FBS to final concentrations of $512 \mathrm{U} / \mathrm{ml}$ to $0.5 \mathrm{U} / \mathrm{ml}$ using an epMotion 5070 automated pipetting system. Culture media was vacuum aspirated from 96-well plates with confluent cell monolayers, $67 \mu \mathrm{l} /$ well of antiviral dilution or control media was added, and plates were again incubated under culture conditions for 24 hours. After 24-hour incubation, cells were challenged with virus (wtVSV, VSV-ZsGreen or VSV-DsRed2, as indicated) in $30 \mu \mathrm{l}$ RPMI media $+2 \%$ FBS per well added to the antiviral dilution for a final multiplicity of infection (MOI) of $5 \mathrm{pfu} / \mathrm{cell}$.

In the standard antiviral assay with wtVSV infection, the infection was allowed to progress until cytopathic effects were readily apparent in unprotected control cells (16-28 hpi, as indicated). The cell medium was discarded, and cells were fixed with a solution of $4 \%$ paraformaldehyde $(\mathrm{w} / \mathrm{v})$ and $5 \%$ sucrose $(\mathrm{w} / \mathrm{v})$ in PBS for 20 minutes. The cells were rinsed twice with PBS (Sigma) and stained with crystal violet $(0.1 \% \mathrm{w} / \mathrm{v})$ in $20 \%$ ethanol overnight.

Alternatively, wtVSV-infected, unfixed assay plates were treated with fluorescent dead cell stain $\left(S_{y} y^{\circ}{ }^{\circ}\right.$ Orange, Invitrogen) 28 hours post-infection as an endpoint fluorescent readout of cell pathology. Fluorescent virus replication was measured without stain or fixation.

\section{Imaging}

Crystal violet staining was measured with a Synergy H4 hybrid multi-mode microplate reader (BioTek) reading absorbance at $570 \mathrm{~nm}$, and scanned using a desktop scanner to obtain reference images. Sytox ${ }^{\circ}$ Orange, $\mathrm{ZsGreen,} \mathrm{and}$ DsRed2 were detected by the microplate reader in fluorescence mode (485/620, 485/528, and 485/620, respectively). All fluorescent assay plates were also scanned with a GE Typhoon FLA 9000 Biomolecular Imager (ZsGreen 489/ 508 nm, DsRed2 555/580 nm, Sytox ${ }^{\oplus}$ Orange 555/580 nm) under BSL 2 conditions.

\section{Image quantification and analysis}

Fluorescent scanning images were analyzed by using JEX, a customized JAVA-based batch processing image analysis 
platform incorporating much of the functionality of Image J (Rasband, 1997-2012) that can be found as shareware at <http://sourceforge.net/projects/jextools $>$. The mean fluorescent intensity of each well was extracted using JEX. Data for all assays were scaled using the following formula:

Sample read-average of uninfected control reads

$\overline{\text { Average of untreated, infected controls-average of uninfected control reads }}$

$\mathrm{IC}_{50}$ value calculations for each dilution series were found by linear least-squares regression through the three data points in the linear range of the dose-response curves closest to half-maximum intensity. Subsequent interpolation determined the standard interferon dilution corresponding to a $50 \%$ decrease in signal above background with respect to the positive (infected, untreated) and negative (uninfected, untreated) control wells. The limit of detection was defined as the minimum interferon concentration that resulted in an $\mathrm{IC}_{50}$ curve that included the $50 \%$ viral inhibition point.

\section{Statistical analysis}

For assay development the antiviral activity of interferon samples were tested in quadruplicate. The intra-assay coefficient of variance (COV) was calculated using the average of the quadruplicate $\mathrm{IC}_{50}$ values and their standard deviation. Inter-assay $\mathrm{COV}$ was calculated using average data from four separate assays and the standard deviation thereof. Comparisons between data sets were conducted using a two-tailed Student's t-test assuming unequal sample variances.

\section{One-step virus infection}

$2 \mathrm{ml} /$ well of PC3 cells were seeded in 6-well plates at a density of $2.510^{5}$ cells/ml and cultured for $24 \mathrm{~h}$ in RPMI supplemented with 10\% FBS, until cells formed 70-90\% confluent monolayers. Cells were then infected with mutant VSV (M51R) at a multiplicity of 5 in $200 \mu \mathrm{l}$ RPMI with $2 \% \mathrm{FBS}$, and cells were incubated at $37^{\circ} \mathrm{C}$ for $1 \mathrm{~h}$ to allow for adsorption with rocking at 20 minute intervals. Mock-infected controls were incubated under $200 \mu \mathrm{l}$ of RPMI media with $2 \%$ FBS. All cells were then rinsed with PBS once to remove unbound virus and $2 \mathrm{ml}$ of RPMI with $2 \%$ FBS was added. Infection was allowed to progress under standard culture conditions. At the indicated times post-infection measured from the initial point of virus addition, supernatants were removed from cells and stored at $-80^{\circ} \mathrm{C}$. The experiment was conducted with full biological duplicates for every sample.

Virus in $400 \mu \mathrm{l}$ of each infection supernatant sample was inactivated by exposure to $7000 \mathrm{~J} / \mathrm{m}^{2} \mathrm{UVC}$ irradiation in standard 24-well tissue culture plates with rocking over 20 minutes. Infection supernatants and corresponding controls were serially diluted in RPMI media with $2 \%$ FBS and antiviral activity was quantified, with technical duplicates, using the antiviral activity assay with the DsRed2-VSV reporter of viral replication. Virus titers from each sample were quantified prior to irradiation using standard plaque assays on BHK monolayers.

\section{Additional files}

Additional file 1: Figure S1. Kinetics of VSV strain growth on A549 cells. A549 cells were infected in parallel wells, $\mathrm{MOI}=10$, and parallel supernatant samples were taken over time and titered by plaque assay.

Additional file 2: Table S1. A brief comparison of several published antiviral assays.

\section{Competing interests}

The authors declare that they have no competing interests.

\section{Authors' contributions}

$\mathrm{EV}$ and $\mathrm{BI}$ carried out the antiviral assays. AB generated the recombinant virus strains. EV, Bi, and JY designed the studies and were responsible for drafting and finalizing the manuscript. All authors read and approved the manuscript.

\section{Acknowledgements}

We thank Dr. Valery Grdzelishvili and Megan Moerdyk-Schauwecker for supplying plasmids, vaccinia virus, and invaluable advice in recombinant virus production. E.V. is supported by the Department of Defense (DoD) National Defense Science \& Engineering Graduate Fellowship (NDSEG) and the National Science Foundation Predoctoral Fellowship. A.B. was supported by an NHGRI Training Grant to the Genomic Sciences Training Program (5T32HG002760). We are grateful for support of this work from the National Institutes of Health (Al091646).

Received: 25 February 2013 Accepted: 24 June 2013

Published: 6 July 2013

\section{References}

1. Isaacs A, Lindenmann J: Virus interference. I. The interferon. Proc Roy Soc Lond Ser B 1957, 147:258-267.

2. Kuri T, Habjan M, Penski N, Weber F: Species-independent bioassay for sensitive quantification of antiviral type I interferons. Virol J 2010, 7:50.

3. Kawaguchi S, Ishiguro Y, Imaizumi T, Mori F, Matsumiya T, Yoshida H, Ota K, Sakuraba H, Yamagata K, Sato Y, et al: Retinoic acid-inducible gene-I is constitutively expressed and involved in IFN-gamma-stimulated CXCL911 production in intestinal epithelial cells. Immunol Lett 2009, 123:9-13.

4. Randall RE, Goodbourn S: Interferons and viruses: an interplay between induction, signalling, antiviral responses and virus countermeasures. J Gen Virol 2008, 89:1-47.

5. Ank N, West H, Bartholdy C, Eriksson K, Thomsen AR, Paludan SR: Lambda interferon (IFN-lambda), a type III IFN, is induced by viruses and IFNs and displays potent antiviral activity against select virus infections in vivo. J Virol 2006, 80:4501-4509.

6. Kotenko SV, Gallagher G, Baurin W, Lewis-Antes A, Shen ML, Shah NK, Langer JA, Sheikh F, Dickensheets H, Donnelly RP: IFN-lambda s mediate antiviral protection through a distinct class II cytokine receptor complex. Nat Immunol 2003, 4:69-77.

7. Meager A, Visvalingam K, Dilger P, Bryan D, Wadhwa M: Biological activity of interleukins-28 and-29: Comparison with type I interferons. Cytokine 2005, 31:109-118.

8. Sheppard P, Kindsvogel W, Xu WF, Henderson K, Schlutsmeyer S, Whitmore TE, Kuestner R, Garrigues U, Birks C, Roraback J, et al: IL-28, IL-29 and their class II cytokine receptor IL-28R. Nat Immunol 2003, 4:63-68.

9. Zhou ZL, Hamming OJ, Ank N, Paludan SR, Nielsen AL, Hartmann R: Type III interferon (IFN) induces a type I IFN-like response in a restricted subset of cells through signaling pathways involving both the Jak-STAT pathway and the mitogen-activated protein kinases. J Virol 2007, 81:7749-7758.

10. Jewell NA, Cline T, Mertz SE, Smirnov SV, Flano E, Schindler C, Grieves JL, Durbin RK, Kotenko SV, Durbin JE: Lambda Interferon Is the Predominant 
Interferon Induced by Influenza A Virus Infection In Vivo. J Virol 2010, 84:11515-11522.

11. Khaitov MR, Laza-Stanca V, Edwards MR, Walton RP, Rohde G, Contoli M, Papi A, Stanciu LA, Kotenko SV, Johnston SL: Respiratory virus induction of alpha-, beta- and lambda-interferons in bronchial epithelial cells and peripheral blood mononuclear cells. Allergy 2009, 64:375-386.

12. Canosi U, Mascia M, Gazza L, SerlupiCrescenzi O, Donini S, Antonetti F, Galli G: A highly precise reporter gene bioassay for type I interferon. J Immunol Methods 1996, 199:69-76.

13. Seo YJ, Kim GH, Kwak HJ, Nam JS, Lee HJ, Suh SK, Baek KM, Sohn Y, Hong $\mathrm{SH}$ : Validation of a HeLa Mx2/Luc Reporter Cell Line for the Quantification of Human Type I Interferons. Pharmacol 2009, 84:135-144.

14. Kugel D, Pulverer JE, Koster M, Hauser H, Staeheli P: Novel Nonviral Bioassays for Mouse Type I and Type III Interferon. J Interferon Cytokine Res 2011, 31:345-349.

15. Larocque L, Bliu A, Xu RR, Diress A, Wang JZ, Lin RT, He RT, Girard M, Li XG: Bioactivity Determination of Native and Variant Forms of Therapeutic Interferons. J Biomed Biotechnol 2011, Article ID 174615, 11 pages.

16. Burgi MD, Prieto C, Etcheverrigaray $M$, Kratje R, Oggero M, Bollati-Fogolin M: WISH cell line: From the antiviral system to a novel reporter gene assay to test the potency of human IFN-alpha and IFN-beta. J Immunol Methods 2012, 381:70-74

17. Lewis JA: A Sensitive Biological Assay for Interferons. J Immunol Methods 1995, 185:9-17.

18. Borderia AV, Hartmann BM, Fernandez-Sesma A, Moran TM, Sealfon SC: Antiviral-Activated Dendritic Cells: A Paracrine-Induced Response State. $\mathrm{J}$ Immunol 2008, 181:6872-6881.

19. Miller-Jensen K, Janes KA, Brugge JS, Lauffenburger DA: Common effector processing mediates cell-specific responses to stimuli. Nat 2007, 448:604-608.

20. Bauer AL, Beauchemin CAA, Perelson AS: Agent-based modeling of hostpathogen systems: The successes and challenges. Inform Sci 2009, 179:1379-1389.

21. Duca KA, Lam V, Keren I, Endler EE, Letchworth GJ, Novella IS, Yin J: Quantifying viral propagation in vitro: Toward a method for characterization of complex phenotypes. Biotechnol Prog 2001, 17:1156-1165.

22. Haseltine EL, Lam V, Yin J, Rawlings JB: Image-guided modeling of virus growth and spread. Bull Math Biol 2008, 70:1730-1748.

23. Howat TJ, Barreca C, O'Hare P, Gog JR, Grenfell BT: Modelling dynamics of the type I interferon response to in vitro viral infection. $J R$ Soc Interface 2006, 3:699-709

24. Lam V, Duca KA, Yin J: Arrested spread of vesicular stomatitis virus infections in vitro depends on interferon-mediated antiviral activity. Biotechnol Bioeng 2005, 90:793-804.

25. Rubinstein S, Familletti PC, Pestka S: A convenient assay for interferons. J Virol 1981, 37:755-758.

26. Berger Rentsch M, Zimmer G: A Vesicular Stomatitis Virus Replicon-Based Bioassay for the Rapid and Sensitive Determination of Multi-Species Type I Interferon. PLoS One 2011, 6:e25858.

27. Ahmed M, McKenzie MO, Puckett S, Hojnacki M, Poliquin L, Lyles DS: Ability of the matrix protein of vesicular stomatitis virus to suppress beta interferon gene expression is genetically correlated with the inhibition of host RNA and protein synthesis. J Virol 2003, 77:4646-4657.

28. Rentsch MB, Zimmer G: A Vesicular Stomatitis Virus Replicon-Based Bioassay for the Rapid and Sensitive Determination of Multi-Species Type I Interferon. PLoS One 2011, 6(10):e25858.

29. Dcunha J, Ramanujam S, Wagner RJ, Witt PL, Knight E, Borden EC: In vitro and in vivo secretion of human ISG15, an IFN-induced immunomodulatory cytokine. J Immunol 1996, 157:4100-4108.

30. Malakhova OA, Yan M, Malakhov MP, Yuan YZ, Ritchie KJ, Kim KI, Peterson LF, Shuai K, Zhang DE: Protein ISGylation modulates the JAK-STAT signaling pathway. Genes Dev 2003, 17:455-460.

31. Zhao C, Denison C, Huibregtse JM, Gygi S, Krug RM: Human ISG15 conjugation targets both IFN-induced and constitutively expressed proteins functioning in diverse cellular pathways. Proc Natl Acad Sci USA 2005, 102:10200-10205.

32. Bose S, Kar N, Maitra R, DiDonato JA, Banerjee AK: Temporal activation of NF-kappa B regulates an interferon-independent innate antiviral response against cytoplasmic RNA viruses. Proc Natl Acad Sci USA 2003. 100:10890-10895.
33. Muruve DA, Petrilli V, Zaiss AK, White LR, Clark SA, Ross PJ, Parks RJ, Tschopp $\mathrm{J}$ : The inflammasome recognizes cytosolic microbial and host DNA and triggers an innate immune response. Nat 2008, 452:103-107.

34. Poeck H, Bscheider M, Gross O, Finger K, Roth S, Rebsamen M Hannesschlager N, Schlee M, Rothenfusser S, Barchet W, et al: Recognition of RNA virus by RIG-I results in activation of CARD9 and inflammasome signaling for interleukin 1 beta production. Nat Immunol 2010, 11:63-69.

35. Buttmann $M$, Berberich-Siebelt $F$, Serfling E, Rieckmann P: Interferon-beta is a potent inducer of interferon regulatory factor-1/2-dependent IP-10/CXCL10 expression in primary human endothelial cells. J Vasc Res 2007, 44:51-60.

36. Hagele H, Allam R, Pawar RD, Reichel CA, Krombach F, Anders HJ: DoubleStranded DNA Activates Glomerular Endothelial Cells and Enhances Albumin Permeability via a Toll-Like Receptor-Independent Cytosolic DNA Recognition Pathway. Am J Pathol 2009, 175:1896-1904.

37. Kumar A, Zhang J, Yu FSX: Toll-like receptor 3 agonist poly(l:C)-induced antiviral response in human corneal epithelial cells. Immunol 2006, 117:11-21.

38. Kelly EJ, Nace R, Barber GN, Russell SJ: Attenuation of Vesicular Stomatitis Virus Encephalitis through MicroRNA Targeting. J Virol 2010, 84:1550-1562.

39. Lecellier CH, Dunoyer P, Arar K, Lehmann-Che J, Eyquem S, Himber C, Saib A, Voinnet $O$ : A cellular microRNA mediates antiviral defense in human cells. Sci 2005, 308:557-560.

40. Mittelbrunn M, Sanchez-Madrid F: Intercellular communication: diverse structures for exchange of genetic information. Nat Rev Mol Cell Biol 2012, 13:328-335

41. Whelan SPJ, Ball LA, Barr JN, Wertz GTW: Efficient recovery of infectious Vesicular Stomatitis virus entirely from cDNA clones. Proc Natl Acad SCi USA 1995, 92:8388-8392.

42. Lawson ND, Stillman EA, Whitt MA, Rose JK: Recombinant Vesicular Stomatitis Virus from DNA. Proc Natl Acad Sci USA 1995, 92:4477-4481.

43. Grdzelishvili VZ, Smallwood S, Tower D, Hall RL, Hunt DM, Moyer SA: Identification of a new region in the vesicular stomatitis virus $L$ polymerase protein which is essential for mRNA cap methylation. Virol 2006, 350:394-405.

44. Das SC, Nayak D, Zhou Y, Pattnaik AK: Visualization of intracellular transport of vesicular stomatitis virus nucleocapsids in living cells. J Virol 2006, 80:6368-6377.

45. Ferran MC, LucasLenard JM: The vesicular stomatitis virus matrix protein inhibits transcription from the human beta interferon promoter. J Virol 1997, 71:371-377.

46. Ahmed M, Lyles DS: Effect of vesicular stomatitis virus matrix protein on transcription directed by host RNA polymerases I, II, and III. J Virol 1998, 72:8413-8419

47. Fuerst TR, Niles EG, Studier FW, Moss B: Eukaryotic transient-expression system based on recombinant vaccinia virus that synthesizes bacteriophage T7 RNA polymerase. Proc Natl Acad Sci USA 1986, 83:8122-8126.

doi:10.1186/1743-422X-10-224

Cite this article as: Voigt et al: A quantitative infection assay for human type I, II, and III interferon antiviral activities. Virology Journal 2013 10:224.

\section{Submit your next manuscript to BioMed Central and take full advantage of:}

- Convenient online submission

- Thorough peer review

- No space constraints or color figure charges

- Immediate publication on acceptance

- Inclusion in PubMed, CAS, Scopus and Google Scholar

- Research which is freely available for redistribution 